\title{
TOPOGRAFIA DO CONE MEDULAR NO TAMANDUÁ-MIRIM (Tamandua tetradactyla Linnaeus, 1758) (XENARTHRA: MYRMECOPHAGIDAE)
}

\section{Topography of the medullar cone in lesser anteater (Tamandua tetradactyla Linnaeus, 1758)}

\author{
MACHADO, G.V. ${ }^{1}$; SANTOS, B.S. ${ }^{2}$ \\ ${ }^{1}$ Médico Veterinário, Mestrado e Doutorado em Anatomia Veterinária pela USP, Professor (Associado I) de \\ Anatomia Veterinária da UFPR/Campus Palotina. \\ 2 Médica Veterinária, Mestre em Patologia Animal pela UFV, Professora de Anatomia Veterinária na \\ UNISEP/Dois Vizinhos..
}

Endereço para correspondência: Gilberto Valente Machado - machadogv@yahoo.com.br.

\section{RESUMO}

Objetivando a busca de dados relativos à topografia do cone medular, foram dissecados três espécimes adultos de tamanduá-mirim (Tamandua tetradactyla), todos machos, os quais foram previamente fixados em solução aquosa de formol a 10\%, e mantidos em solução semelhante. Após o afastamento da pele e remoção da musculatura epiaxial, procedeu-se a remoção dos arcos vertebrais, em toda a extensão da coluna vertebral, visualizando-se assim a medula espinhal in situ. A base do cone medular foi registrada na altura da vértebra $L 1$, e sua extremidade anotada, em todos os animais estudados, entre a quinta (L5) e sexta (L6) vértebras lombares, o que denota um longo e afilado cone medular, acompanhado pela cauda eqüina. Ressalte-se que a espécie em apreço apresenta seis vértebras lombares.

Palavras-chave: medula espinhal, cone medular, tamanduá-mirim.

\section{ABSTRACT}

Aiming at the search of data to the topography of the medullar cone, three adult lesser anteater (Tamandua tetradactyla), all males, were dissected, which were previously fixed in $10 \%$ aqueous formalin solution, and maintained in similar solution. Following skin incision, the epiaxial musculature and vertebral arches were removed in the whole extension of the vertebral column, was observed a very long and thin medullar cone, with his base located at first lumbar vertebra (L1) and the apex between L5 and L6 vertebrae. This Tamandua tetradactyla presented six lumbar vertebrae.

Key words: spinal cord, medullar cone, lesser anteater.

\section{INTRODUÇÃO}

O tamanduá-mirim (Tamandua tetradactyla Linnaeus, 1758) é um mamífero pertencente à Ordem Xenarthra, Família Myrmecophagidae, encontrado da
América Central à América do Sul, a leste dos Andes. Sua morfologia é pouco conhecida, salvo aspectos gerais, o que sinaliza para a necessidade da ampliação dessas informações, especialmente as que venham de encontro ao interesse médico- 
veterinário, ou seja, de cunho aplicado, ou que possam contribuir com medidas que visem a preservação da espécie. Em atenção ao interesse da anatomia comparativa, e com vistas a oferecer informações, de cunho anatômico, que possam servir de base para a aplicação das anestesias epidurais, cuja importância é ressaltada por Hopkins (1935), o presente trabalho objetiva oferecer dados relativos à topografia do cone medular dessa espécie. Referindo-se aos animais domésticos, Dyce et al. (1997) afiançam que a terminação da medula espinhal varia entre as espécies, ocorrendo em L5 ou L6 nos suínos, em L6 nos ruminantes, L6 ou L7 no cão, S2 no eqüino $e$, mais variavelmente, entre L6 e S3 no gato. Tais dados são corroborados por Habel (1951), Seiferle (1951), Barry (1956), Schwarze e Schröder (1972), Getty (1975) e Bruni e Zimmerl (1977). Reportando-se ao cão, Santiago (1974) anuncia que a base do cone medular se encontra na altura da terceira vértebra lombar (L3) e seu ápice é registrado em $\mathrm{L} 7$. Por outro lado, referindose aos caprinos, Santiago et al. (1990), situam o ápice do cone medular entre as vértebras L5 e L6. Fletcher (1979) afirma que em cães de grande porte a extremidade do cone medular acha-se junto à margem cranial da sétima vértebra lombar (L7), ao passo que em cães de pequeno porte encontra-se na altura da sexta vértebra lombar (L6). Entretanto, Evans e De Lahunta (1994), também se reportando ao cão, afirmam que o cone medular tem sua base formada pelo sétimo segmento lombar da medula espinhal (L7) e que seu ápice é constituído pelo último segmento caudal (Ca5); afirmam ainda encontrar-se esse último na altura da sexta vértebra lombar (L6).

Em espécies não domésticas, o tema é abordado por Machado et al. (1992), em sagüis (Calitrix jacus jacus), localizando o cone medular entre as vértebras L2 e L4; por Machado et al. (2002), no lobo-guará (Chrysocyon brachyurus), quando situam o ápice do cone medular entre as vértebras L3 e L6; e Machado et al. (2003), no lobomarinho (Arctocephalus australis), cuja localização inusitada do cone medular o situa entre as vértebras T5 e T7, caracterizando desta feita uma topografia até então nunca registrada em outros mamíferos. Ainda em relação aos animais silvestres, Carvalho et al. (2003) registraram a ocorrência do cone medular de um gato-mourisco (Herpailurus yagouaroundi), cuja base achava-se na altura da vértebra L6 e seu ápice em S2.

\section{MATERIAL E MÉTODOS}

Foram utilizados três exemplares adultos, machos, de tamanduá-mirim (Tamandua tetradactyla), encontrados já em óbito junto às margens da rodovia BR 277, e encaminhados ao Laboratório de Anatomia Veterinária da UFPR/Campus Palotina. Em laboratório, aqueles espécimes tiveram o seu sistema arterial injetado com solução corada de Neoprene látex (Dupont do Brasil S/A), através da artéria carótida comum direita, abordada por incisão cervical mediana ventral. Em seguida foram fixados com solução aquosa de formol a $10 \%$, injetada com seringas e agulhas por todas as partes moles do corpo e cavidades corporais. Após os procedimentos descritos, os animais foram mergulhados em tanques contendo solução aquosa de formol a $10 \%$ e ulteriormente dissecados. Para a observação e análise do cone medular, foi realizada a dissecação, mediante incisão longitudinal da pele na linha mediana dorsal, desde a região cervical cranial até a base da cauda; após o afastamento da pele, promoveu-se a remoção da musculatura epiaxial, com a conseqüente exposição da coluna vertebral, em seguida foram retirados os arcos vertebrais e exposta a medula espinhal contida em seus envoltórios. Após a identificação das vértebras regionais últimas torácicas, lombares e sacrais -, foi realizada uma incisão longitudinal das 
meninges espinhais no terço caudal da medula, evidenciando assim o cone medular e a sua relação esqueletópica com as vértebras. As observações foram registradas por fotografias e os resultados anotados para sua descrição.

\section{RESULTADOS}

A dissecação de três espécimes adultos, machos, de tamanduá-mirim (Tamandua tetradactyla), objetivando conhecer as relações topográficas do cone medular, onde foram notadas seis vértebras lombares, permitiu observar que: a) o cone medular apresenta-se delgado e longo, medindo, da base ao ápice, $7,00 \mathrm{~cm}$ em dois animais $(66,66 \%)$, e $6,5 \mathrm{~cm}$ em um animal $(33,33 \%)$; b) a base do cone medular, juntamente com o início da cauda eqüina, acha-se na altura da primeira vértebra lombar (L1) e seu ápice entre as vértebras L5 e L6, nos três espécimes examinados (tabela 1); c) a intumescência lombar, que precede a base do cone medular, foi registrada ao nível das duas últimas vértebras torácicas.

Tabela 1 - Representação da topografia do cone medular, base e ápice, e seu comprimento, em três exemplares de tamanduá-mirim (Tamandua tetradactyla). Palotina/PR, 2008.

\begin{tabular}{lccc}
\hline Animal N & Base do & $\begin{array}{c}\text { Ápice } \\
\text { do } \\
\text { cone }\end{array}$ & $\begin{array}{c}\text { Comprimento } \\
\text { do cone }\end{array}$ \\
\hline 01 & L1 & L5-6 & $6,50 \mathrm{~cm}$ \\
02 & L1 & L5-6 & $7,00 \mathrm{~cm}$ \\
03 & L1 & L5-6 & $7,00 \mathrm{~cm}$
\end{tabular}

\section{DISCUSSÃO}

Numerosos autores têm se reportado à topografia do cone medular, em diferentes espécies animais, tanto pela importância do tema quando relacionado à prática das anestesias epidurais quanto pelo interesse da anatomia comparativa. Nesse contexto, enquadram-se as observações de Hopkins (1935), Habel (1951), Seiferle (1951), Barry (1956), Schwarze e Schröder (1972), Santiago (1974), Getty (1975), Bruni e Zimmerl (1977), Fletcher (1979), Santiago et al. (1990), Evans e De Lahunta (1994) e Dyce et al. (1997), que se referem aos animais domésticos, assim como os achados de Machado et al. (1992, 2002 e 2003) e de Carvalho et al. (2003), relativos a outros mamíferos, não domésticos.

Considerando que nenhuma referência foi encontrada, na literatura consultada, sobre o tema de interesse do presente trabalho, relacionada aos Xenarthras, serão enfatizados, nesta discussão, os registros feitos em animais silvestres, como em Machado et al. (1992), quando apontam a terminação do cone medular no sagüi (Calitrix jacus jacus) entre as vértebras L2 e L4; também em Machado et al. (2002), referindo-se ao lobo-guará (Chrysocyon brachyurus), o ápice do cone medular é apontado entre as vértebras L3 e L6; e ainda, em Machado et al. (2003) quando, no lobo-marinho (Arctocephalus australis), anotam a localização inusitada do cone medular entre as vértebras T5 e T7. As anotações supra não se assemelham, tanto na topografia quanto nas dimensões do cone medular, às que ora se apresentam, no tamanduá-mirim (Tamandua tetradactyla), cujo cone medular se apresenta relativamente longo e delgado, tendo sua base situada na altura de $L 1$ e seu ápice entre as vértebras L5 e L6 (figura 1). Cabe cotejar, ainda, os registros de Carvalho et al. (2003), realizados em um exemplar de gatomourisco (Herpailurus yagouaroundi), que situam o cone medular entre as vértebras L6 (base do cone) e S2 (ápice).

Portanto, com base nos registros feitos, após dissecação de três exemplares de tamanduá-mirim (Tamandua tetradactyla), machos, adultos, julga-se 


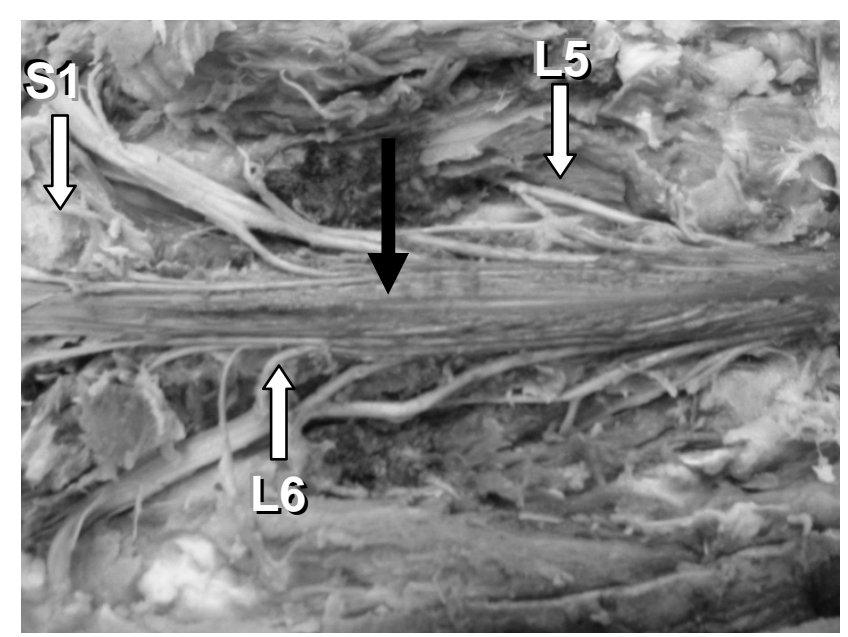

Figura 1 - Fotografia, em vista dorsal, da terminação da medula espinhal de tamanduámirim (Tamandua tetradactyla), cujo ápice do cone medular (seta preta) acha-se entre as vértebras L5 e L6. Palotina/PR, 2008.

poder afirmar que 0 cone medular apresenta-se relativamente longo $(6,5 \mathrm{~cm}$ a $7,00 \mathrm{~cm}$ ) e delgado, sua base acha-se na altura da primeira vértebra lombar (L1) e seu ápice entre as vértebras L5 e L6. Tais achados, apesar do pequeno número de animais estudados, vêm de encontro ao interesse da prática das anestesias epidurais, indicando, como sítio provável para a colocação de agulhas, o espaço interarqueado situado entre as vértebras L6 e S1.

\section{REFERÊNCIAS}

BARRY, A. A quantitative study of praenatal changes in angulation of spinal nerves. Anatomical Record, v.126, n.1, p.97-109, 1956.

BRUNI, A.C.; ZIMMERL, U. Anatomia degli animali domestici. Milano: Francesco Vallardi, 1977. v.2, p.536.

CARVALHO, S.F.M.; SANTOS, A.L.Q.; AVILA JUNIOR, R.H.; ANDRADE, M.B.; MAGALHĀES, L.M.; MORAES, F.M.; RIBEIRO, P.I.R. Topografia do cone medular em um gato-mourisco, Herpailurus yagouaroundi (Severtow, 1858) (FELIDAE). Archives of Veterinary Science, Curitiba, PR, v.8, n.2, p.35-38, 2003.
DYCE, K.M.; SACK, W.O.; WENSING, C.J.G. Tratado de anatomia veterinária. 2. ed. Rio de Janeiro: Guanabara Koogan, 1997, p.238-241.

EVANS, H.E.; De LAHUNTA, A. Miller guia para a dissecação do cão. 3. ed. Rio de Janeiro: Guanabara Koogan, 1994. p.197.

FLETCHER, T.F. Spinal cord and meninges. In: EVANS, H.E.; CHRISTENSEN, G.C. Miller's anatomy of the dog. 2. ed. Philadelphia: W.B. Saunders Company, 1979. p.947.

GETTY, R. Sisson and Grossman's the anatomy of the domestic animals. 5. ed. Philadelphia: W.B. Saunders Company, 1975. v.1, p.202-204.

HABEL, R.E. Guide to the dissection of the Cow. New York: Cornell Cooperative Society, 1951. p.41.

HOPKINS, G.S. The correlation of anatomy and epidural anesthesia in domestic mammals. Cornell Veterinarian, Ithaca, NY, v.25, p.263-270, 1935.

MACHADO, G.V.; RIELLA, A.C.M.; LIEGEL, S.R. Esqueletopia do cone medular em Calitrix jacus jacus. CONGRESSO BRASILEIRO DE MEDICINA VETERINÁRIA, 22, 1992, Curitiba. Anais, 1992. p.56.

MACHADO, G.V.; FONSECA, C.C.; DAS NEVES, M.T.D.; DE PAULA, T.A.R.; BENJAMIN, L.A. Topografia do cone medular no lobo-guará (Chrysocyon brachyurus Illiger, 1815). Revista Brasileira de Ciência Veterinária, Niterói, RJ, v.9, n.2, p.107-109, 2002.

MACHADO, G.V.; LESNAU, G.G.; BIRCK, A.J. Topografia do cone medular no lobo-marinho (Arctocephalus australis Zimmermann, 1803). Arquivos de Ciências Veterinárias e Zoologia da UNIPAR, Umuarama, PR, v.6, n.1, p.11-14, 2003.

SANTIAGO, W. Esqueletopia do cone medular em Canis familiaris. Arquivo da Universidade Federal Rural do Rio de Janeiro, Seropédica, RJ, v.4, n.1, p.67-69, 1974.

SANTIAGO, W.; MACHADO, G.V.; VIZIOLI, V.P.; BARRA, P.H.M. Esqueletopia do cone medular em caprinos mestiços. CONGRESSO MINEIRO DE MEDICINA VETERINÁRIA, 9, 1990, Belo Horizonte. Anais, 1990. p.107.

SCHWARZE, E.; SCHRÖDER, L. Compendio de anatomía veterinária. Zaragoza: Acribia, 1972. p.26-27.

SEIFERLE, E. On the topography of the equine and bovine spinal cord. Zeitschrift für Anatomie, v.110, p.731-784, 1951. 